\title{
O TRABALHO DO ATOR NO CONTEXTO DAS MINISSÉRIES BRASILEIRAS
}

\author{
Isabel Orofino ${ }^{1}$
}

\section{Resumo}

$\mathrm{O}$ artigo traz uma reflexão sobre o trabalho de atores e atrizes no âmbito da indústria cultural brasileira, em especial a cena das minisséries realizadas pela Rede Globo de televisão. Discutem-se, a partir de uma teoria da estruturação e mediações, possibilidades de inserção critica e uso reflexivo das estruturas comerciais de produção por parte dos atores na construção de estéticas diferenciadas.

Palavras-chave: atuação, indústria cultural brasileira, reflexividade, mediações.

\begin{abstract}
The article proposes a discussion about the work of actors and actresses within the context of the Brazilian culture industry, in special the scene of the miniseries produced by Rede Globo Television network. The debate is constructed within the framework of a theory of structuration and mediations with the focus on the critical insertion and reflexive use of the commercial structures of production by the actors in the construction of particular aesthetics.
\end{abstract}

Keywords: acting, brazilian culture industry, reflexivity, mediations.

"Uma pesquisa séria e exaustiva poderia proporcionar uma surpresa a todos aqueles que encaram a televisão como um meio 'menor'. A despeito de todos os discursos popularescos e mercadológicos que tentaram e ainda tentam explicá-la, a televisão acumulou, nestes últimos cinqüenta anos de sua história, um repertório de obras criativas muito maior do que normalmente se supõe, um repertório suficientemente denso e amplo para que se possa incluí-la sem esforço entre os fenômenos culturais mais importantes de nosso tempo." (MACHADO, 2001, p. 15).

\section{Introdução}

Colocar em debate o trabalho do ator no âmbito da produção de televisão tem sido muitas vezes uma tarefa inglória. Em boa parte dos círculos acadêmicos a que tenho acesso, em especial aqueles que tratam das práticas

${ }^{1}$ Doutora em Ciências da Comunicação pela Universidade de São Paulo. Professora na Graduação e PósGraduação na área de Estudos de Mídia, Comunicação e Artes Cênicas - Centro de Artes (CEART) - Universidade do Estado de Santa Catarina (UDESC). 
de interpretação/atuação, quando se trata de televisão na maioria das vezes a visão que predomina é aquela que acusa a TV como lugar da reprodução das ideologias das classes dominantes, ou que perpetua o ideário da sociedade do consumo e do mercado, ou ainda aquela em que o trabalho do ator não passa de uma prática superficial, funcional e alienada. Muito embora no âmbito da pesquisa de comunicação os estudos críticos sobre a televisão tenham sofrido uma mudança radical no Brasil, nos estudos de teatro e dramaturgia a visão apocalíptica com relação à TV tende ainda a prevalecer.

Neste sentido, a proposta que apresento neste artigo é situar algumas contribuições teóricas recentemente desenvolvidas na América Latina a partir dos anos 80 do século passado, conhecidas como teorias das mediações. Estas abordagens situam a televisão como um espaço contraditório que, como destaca Jesús Martín-Barbero (1997), não apenas atende aos interesses perversos das indústrias culturais, mas que também responde às demandas sociais, aos gostos populares, aos modos como as pessoas, em variados contextos e situações, se vêem e se reconhecem.

Cabe também destacar que a televisão brasileira, ao longo de sua trajetória, tem sido responsável pela formação de uma classe artística significativa, proporcionando espaço de experimentação e treinamento de profissionais nos mais variados campos de atuação, desde roteiristas, diretores, produtores, cenógrafos, figurinistas, músicos, compositores e também atores e atrizes. No que se refere aos profissionais da arte de representar a televisão brasileira tem garantido um espaço merecedor de atenção e problematização na medida em que tem formado uma classe de atores e atrizes "multivalentes" (OROFINO, 2009), pois atuam tanto para a TV como para o cinema e o teatro. Há uma nova geração de atores e atrizes que formam um elenco significativo que se inserem nesta classificação, eu destaco alguns: Marco Ricca, Chico Diaz, Leona Cavalli, Selton Mello, Matheus Nachtergaele, Dira Paes, Caio Blat, Simone Spolatore, Lázaro Ramos, entre outros. E isto não é diferente quando se analisa uma história social da TV com o foco no trabalho dos atores, verifica-se a presença permanente do diálogo com o teatro, seja pelo formato do teleteatro, seja pela inserção do profissional nos dois âmbitos da produção cultural.

Neste sentido, não acredito que seja possível hoje estabelecer uma fronteira rígida com relação ao trabalho do ator em relação a estas diferentes formas culturais, visto que, como destacou Guel Arraes (cf. OROFINO, 2006) em muitas situações não há tanta diferença em se realizar um trabalho experimental para TV e um filme conceitual para o cinema. Outro ângulo a ser enfocado é a presença das mídias nos palcos contemporâneos. Verifica-se uma inserção da imagem videográfica de variadas maneiras no palco, o que 
traz a atuação mediada pela tecnologia também para a cena do teatro. Todas estas questões tornam o debate sobre o trabalho do ator contemporâneo e suas inter-relações com as mídias eletrônicas e digitais um terreno pantanoso que demanda estudo e reflexão.

Para a construção deste artigo defendo a hipótese de que, de fato a TV brasileira se caracteriza com um dos grandes laboratórios de criação e interpretação dramática que temos no país. E ainda que haja muito preconceito com relação ao trabalho dramatúrgico que se realiza na televisão cotidianamente, buscarei demonstrar, a partir das vozes de três atores profissionais que, a TV brasileira - sobretudo a partir do espaço que se consolidou na feitura das minisséries - em alguma medida pode ser "levada a sério" (MACHADO, 2001).

Na seqüência deste texto vou lançar mão de depoimentos recolhidos ao longo de minha pesquisa sobre as práticas profissionais no contexto da indústria cultural no Brasil, em especial a Rede Globo de Televisão. Naquela ocasião eu buscava mapear uma etnografia da produção verificando as práticas de diferentes profissionais vinculados ao Núcleo Guel Arraes e a realização da minissérie O Auto da Compadecida. Foram entrevistados diferentes profissionais como o próprio diretor Guel Arraes, a roteirista Adriana Falcão, a cenógrafa Érika Lovisi, o produtor de arte Moa Batsow, entre outros. Para este artigo eu selecionei apenas os depoimentos dos atores da minha amostragem, a saber: Rogério Cardoso, Marco Nanini e Selton Melo. Em termos metodológicos eu realizei entrevistas semi-estruturadas e em profundidade sobre suas práticas profissionais e o sentido das suas inserções no contexto da indústria cultural da televisão.

Como método de exposição eu priorizei, nas páginas a seguir: em primeiro lugar uma reflexão sobre como a televisão se caracteriza enquanto lugar de formação de atores, com ênfase para a experiência de Selton Melo, cuja formação se dá desde a infância no ambiente da TV comercial. Em segundo lugar busco evidenciar que os atores profissionais de certa forma usam as estruturas comerciais de produção para atingirem diferentes objetivos que variam desde a questão financeira, a formação, a visibilidade e a criação. No tópico seguinte coloco em discussão o processo de construção das personagens, aqui com ênfase à prática desenvolvida por Guel Arraes naquele contexto em particular. Convém destacar que a questão do treinamento de atores não é debatida neste segmento, salienta-se apenas que há diferentes práticas e que neste contexto, o diretor optou por um longo período de ensaios que antecederam a etapa das gravações, situando aí um espaço híbrido entre práticas teatrais e televisivas. Para concluir destaco as contribuições das teorias das mediações em particular o conceito de mediação videotecnológica. Trata-se de um corpus teórico amplo que se propõem a investigar os modos como os sujeitos sociais dialogam com os 
meios massivos de comunicação a partir de uma perspectiva de negociações na produção de sentidos, que se estende da produção à recepção, mediatizados pela textualidade em jogo. O conceito de mediação videotecnológica, com enfoque na temática da atuação, será usado aqui como um recurso que busca evidenciar não apenas a presença do ator como componente da cena, mas como "compositor" (BONFITTO, 2002) de situações dramáticas a partir do uso reflexivo do seu corpo em relação a toda a rigidez das estruturas comerciais de produção.

\section{O processo de formação}

A partir da análise dos depoimentos destes atores confirma-se que, desde o surgimento da TV há um processo de formação de atores que se dá, além da prática efetiva do teatro e cinema, também a partir das dinâmicas da produção de televisão. É o caso destes dois profissionais que entrevistamos. $\mathrm{O}$ ator Rogério Cardoso, por exemplo, explicou como a sua formação difere de grande parte de atores mais jovens, como é o caso de Selton Melo, apresentado na seqüência:

Teatro eu fiz toda minha vida, em paralelo. Às vezes fazia mais teatro, às vezes fazia menos porque a televisão, antigamente era muito complicada pois era tudo ao vivo. E isso te obrigava a trabalhar diariamente na televisão, então atrapalhava muito o teatro. Mas quando começou o videotape, as coisas começaram a ficar tecnicamente mais fáceis, a gente conseguiu fazer mais teatro. Hoje, a gente faz regularmente teatro. Quem gosta, né? Claro. São espaços diferentes, técnicas diferentes. Mas todos são formados na arte de representar. $A$ arte de representar é a mesma, agora a técnica se aplica a cada linguagem. Na televisão, eu acredito que apareça mais o diretor. É mais a arte do diretor. E como a riqueza da técnica é maior, a técnica é muito grande, você tem muito mais recursos, você pode dispensar até o ator. $O$ cinema também faz. Por exemplo: pode-se fazer a sua parte todinha, um diálogo nosso, você grava a sua parte sem nunca precisar eu estar junto, certo? Então é, fica uma coisa realmente, eu diria, pasteurizada, do jeito que você quiser adjetivar. Porque prescinde um pouco do ator, prescinde do talento do ator (CARDOSO, 2001).

O depoimento do ator Selton Melo explicita a polêmica, afinal ele é considerado pela crítica como um dos grandes atores do cinema e da televisão, e não se pode conceituar o seu trabalho como "algo pasteurizado":

A minha formação, por exemplo, é dentro da $T V$. Eu não sou um ator de teatro. Eu cresci dentro da $T V$, quer dizer, eu cresci com profissionais da TV. É claro que você pode fazer essa mesma trajetória 
e não valer pra nada, mas tem muita coisa boa dentro da indústria. Porque é tudo tão rápido e corrido por ser uma indústria, né? Principalmente em novela, 30 cenas por dia. Mas isso pode ser usado a seu favor, você pode tirar disso grandes coisas, como as pessoas com quem você convive, grandes atores, principalmente os mais velhos. Eu já trabalhei com os maiores atores desse país. Isso não tem escola que me dê. É não tem um ano de escola que me dê seis meses de convivência com Lima Duarte, com Nathalia Timberg, com Cláudio Corrêa e Castro, com Walmor Chagas, com Raul Cortez, Stênio Garcia. São atores que só de você conviver, ouvir o que eles gostam, como foi, como foi a história, como é que é, como é que não é. Só de você estar antenado ali convivendo, é uma grande escola (MELO, 2001).

O ator Marco Nanini, ao falar de sua experiência na TV, informa que a sua formação está fortemente ancorada na prática teatral e destaca alguns aspectos relativos à especificidade da atuação para diferentes formas culturais como o teatro, o cinema e a televisão:

Eu nunca deixo de fazer teatro, eu faço sempre junto teatro. Então vai ficando complicado, às vezes até por uma questão da própria televisão que não tem tempo deu gravar tudo. Então, às vezes, eu não posso fazer mesmo.

O ritmo industrial de produção é avassalador, mas por outro lado, ele provoca uma agilidade de raciocínio, de imaginação. Ou seja, você tem que ser rápido na criação. O próprio cinema oferece isso também, esse tipo de coisa. No cinema, você não tem como no teatro, não ficam dois meses ensaiando uma peça e tal, e é um processo mais lento. Mas o teatro ele tem que ter essa base porque se vai repetir-se muitas vezes, né? No cinema, na televisão, você não repete. Você faz uma duas vezes e acabou a cena. Então você se joga mais rapidamente no precipício, vamos dizer assim. No teatro você vai devagarzinho porque as bases têm que estar muito fundamentadas pra você depois poder repetir, sem perder a qualidade do trabalho, do ponto que você adquiriu. Mas na televisão como não tem esse tempo, você tem que estudar, raciocinar e na hora fazer, seja lá como for, porque se não, não sai. Então isso dá um frenesi que acaba as vezes colaborando pra que você tire o personagem mais rapidamente de dentro de você. Evidentemente se você tivesse que repetir essas cenas sempre, elas iam perdendo o brilho porque o fogo da primeira vez, num é, a adrenalina que você tem na primeira vez, ela não ia estar presente nas outras vezes por isso que no teatro você tem que ser mais cauteloso. Você já tem que projetar a repetição. Então você tem que ter base pra repetir sem perder o fio da meada. Mas na 
televisão o raciocínio pra interpretação, a abordagem é diferente porque você chega na beira do precipício e tem que se jogar. Você tem que tá com pára-quedas, pronto. Então, tem um lado que é desgastante e tem um lado que te ajuda na criatividade também, que é essa premissa, essa rapidez, de você ter que criar rapidamente (NANINI, 2001).

\section{A indústria cultural}

A pesquisa que realizei nesta ocasião buscava problematizar o conceito de mediação tecnológica. Com isso eu tinha a meta de identificar ações reflexivas de determinados sujeitos sociais por dentro das estruturas rígidas da produção cultural comercial. Foi possível naquela ocasião confirmar a hipótese de que a TV produz um número significativo de programas que divergem das normas puramente instrumentais, técnicas e mercantis na difusão de valores ideologicamente comprometidos com valores de uma sociedade capitalista e do consumo. Foi possível verificar que há sujeitos profissionais que atuam por dentro destas estruturas identificando brechas na produção simbólica. Os depoimentos que apresento a seguir confirmam o que acabo de defender, por exemplo, sobre a dinâmica industrial de produção o ator Rogério Cardoso apresenta uma visão crítica e ao destacar que:

Bom, eu diria que o pessoal que faz novela, os colegas, atores de novela já se acostumaram a isso. Então eles fazem uma criação superficial. Os tipos são quase todos estereotipados. Todos os tipos de novela você tem o vilão, você tem o mocinho, você tem a mocinha, mas nada é muito profundo porque não dá tempo de criar nada profundo. Não dá tempo.

Já o Guel Arraes tem uma linguagem pra trabalhar com o ator que tem que ser muito afinada. Por isso que ele acaba fazendo uma espécie de um senadinho de atores que trabalham com ele. Mas é porque ele se acostuma a trabalhar com aqueles atores que compreendem a linguagem dele. Ele é muito rápido, ele é muito rápido. As frases dele são sempre curtas, muito texto então tem que estar muito afiado, tem que dizer exatamente aquilo que está escrito. Você pode até mudar mas desde que você converse com ele. E ele gosta de gente criativa e ele não tolhe isso no ator. Só que o ator tem que andar na métrica dele. Então, ele é maestro mesmo, por isso que dá certo, fica afinado o elenco todo afina, o conjunto afina. Porque não dá pra cada um trabalhar no seu tempo de interpretação. Você tem que entrar no tempo do maestro, é uma orquestra. Então, por mais virtuoses que você tenha, todos têm que trabalhar em orquestra de câmera, junto com o maestro regendo (CARDOSO, 2001). 
O depoimento do ator Marco Nanini também contribuiu para que se identificasse uma idéia diferente sobre a televisão brasileira. Afinal, muito do que a crítica cultural e a teoria da arte e da cultura reservam ao meio televisivo é o entendimento particular de sua submissão ao sistema mercantil de produção. São, em grande parte, teorias lineares, não-dialógicas. Mas há outras relações que se estabelecem neste contexto. É o que se pode verificar a partir do relato a seguir:

Eu tive um encontro muito interessante com o Guel. Um encontro que mexeu muito com a minha cabeça porque era uma outra forma de ver televisão. E como eram programas de uma hora: o Brasil Especial, por exemplo, e Comédia da Vida Privada, eram programas de 45 minutos e a gente fazia em doze dias e era um esquema meio de cinema, onde a figura do ator era muito importante. Todos os atores tinham uma participação de cuidado, de estudo e de discussão com o diretor. E, então, isso mexeu muito comigo e foi quando eu comecei a ter mais intimidade com a câmera, quer dizer, até então eu não ficava com muito medo da câmera. E um exercício de atuar em televisão, porque o Guel tinha critérios sobre atuação, sobre a presença do ator nos programas dele e essa discussão paralelamente ao programa foi muito importante pra mim (NANINI, 2001).

\section{A construção das personagens}

Na sequência apresento alguns trechos das entrevistas com o foco na construção das personagens interpretadas pelos três atores. Aqui eles relatam a experiência de trabalho com Guel Arraes no processo de preparação que aconteceu de um modo muito particular, próprio do trabalho do diretor. A identificação de uma preparação que prima pela "marcação" das cenas revela que há práticas diferenciadas. Com isto quero ressaltar que há alguns trabalhos recentes (cf RIBEIRO, 2005), sobretudo a respeito da preparação de atores no cinema brasileiro contemporâneo que destacam a improvisação como um elemento fundamental. Na prática de Guel Arraes a improvisação tem um lugar pouco explicitado. Pelo contrário, o que a particulariza é justamente a marcação bem definida, a partir da qual e sobre a qual se dá o trabalho criativo do ator. Com a realização de várias entrevistas, inclusive com o próprio Guel Arraes, foi possível identificar que esta preparação se deu inicialmente na casa do próprio diretor com a realização de uma série de leituras dramáticas do roteiro e com o início das marcações de cenas. Posteriormente houve um processo de "imersão" que aconteceu na própria cidade de Cabaceiras, no interior, no sertão de Pernambuco. Selton Melo, que fez o Chicó relata a experiência de como o trabalho do ator enriquece a partir da marcação já fornecida pelo diretor: 
Foi tudo muito ensaiado, como no teatro. Tudo muito ensaiado. Tudo muito marcado. E isso é bom pro ator a partir do momento que você tem as marcas, você só cria em cima daquilo que já tem. Quer dizer, por exemplo hoje, eu vim gravar. Eu não sei a marca. Se a gente já tivesse ensaiado, eu já sabia o que eu ia fazer, ou seja, aí eu vou mais longe ainda. Porque se eu já sei que eu vou sentar, que eu vou pegar nesse gravadorzinho, o ator vai longe. Se eu sei que vou estar com a mão aqui, então eu passava a mão, ia pegar o cigarro, já começa a criar em cima do que já existe. Então é um processo muito criativo, o processo do Guel. Já existe uma cama que a gente prepara que já é muito boa. Se a gente fizer só aquela cama, já vai ficar legal. Só que claro que cada um vem com as suas idéias e suas pinceladas e acaba ficando um trabalho muito rico.

Depois a gente ficou lá no sertão antes de começar a gravar. Isso deu uma vivência pra gente. Então, eram dois sujeitos simplórios e vivendo situações esdrúxulas e divertidas, de uma forma farsesca. E o Guel é um mestre da comédia. Ele sabe mesmo, muito disso, timing de comédia e tudo mais. E tudo muito ensaiado como no teatro (MELO, 2001).

Já o ator Rogério Cardoso, que fez o padre João me explicou como o seu tipo físico de fato pouco contribuía para a construção da sua personagem. Falou também sobre o modo como compreendia a questão da verdade da personagem cômica e o fato de que no humor há um limite tênue, uma fronteira que é definidora da credibilidade e da verossimilhança da personagem:

Eu ouvi comentários do tipo: 'o povo tava acostumado a ver o Rogério Cardoso fazendo os tipos dele na televisão e agora, fazendo um padre?' Bem, o padre João, eu fiz um padre despojado mesmo. No começo, eu fiquei preocupado, falei 'Guel, mas você acha que o pessoal vai aceitar um padre loiro, branquelo, de olho azul, no Nordeste?' Ai ele falou: 'Não, isso é comum lá, porque havia muito holandês, muito francês e essa herança ficou'. No começo, eu pensei em fazer um padre, até estrangeiro. Mas só que aí ia conflitar um pouco porque nenhuma das encenações houve um padre estrangeiro no Auto da Compadecida. Mas nada impede que esse padre João seja um padre Yohan, seja um padre Giovanni, da Itália, mas que foi se aculturando e ficou padre João pro povo. Na verdade, chama Giovanni e ninguém tem nada a ver com isso. Mas aí o Guel falou: 'Não,vamos adotar uma linha mesmo de, vamos assumir o nordeste. Não esquenta a cabeça com isso não. Lá tá cheio de nordestino loirinho'. 
É, o importante que ele tenha 'verdade'. Só! Se o personagem tem verdade, se é verossimil, ele passa. Se não, você não consegue. No humor, se vocêpassa um pouco do limite da verossimilhança, ele deixa de ser crível. E aí ele não cola, não implaca porque ninguém conhece nada parecido. Você quando vê uma personagem, instintivamente, aquilo, inconscientemente, desperta em você imagens que você já conhece. Quando eu faço o Rolando Lero: 'Amado mestre', enrolo as coisas, todo mundo conhece um Rolando Lero. Seja na classe, seja na repartição pública, seja um político que ele viu. Todo mundo conhece um Rolando Lero, um enrolador. Todo mundo conhece, então é verdade aquilo. Eu posso é fazer ele ser um pouco over. Posso fazer um pouco a mais, aí passa a ser uma sátira. Um pouco a mais da verdade, mas nunca pode deixar de ser verdade. Então se você busca a verdade na personagem, se ela tem credibilidade, ela é crivel, é verossímil, ela passa. E aí todo mundo aceita, velho, criança, e coisa e tal. É qualquer estado do Brasil, todo mundo, é verdade, é gente (CARDOSO, 2001).

Marco Nanini que interpretou Severino, o cangaceiro, narrou como foi a construção da personagem que exigiu o uso de um figurino muito particular. Em um trabalho de criação coletiva existe uma a sobreposição de criatividade e aqui resultou na necessidade de o ator conduzir um figurino que primava pelo excesso, o exagero e que pesava sete quilos. Um trabalho assinado pelo figurinista Cao Albuquerque que demandou do ator uma ação diferenciada:

O Severino, o cangaceiro (...) parecia uma árvore de natal, todo cheio de coisas e isso era um desafio porque eu tinha que passar humanidade. Não podia ficar sem carne, osso e sangue, somente com os badulaques. Quer dizer, quanto mais coisa eu botava no personagem, mais eu tinha que prestar atenção na humanidade dele, nos sentimentos, enfim, nas emoções pra que aquilo não ficasse muito frio. A roupa pesava sete quilos. Era um calor muito grande e era muito difícil porque a lente, como se fosse um olho de vidro, me tirava a visão de um olho e por causa disso eu também ouvia menos, não sei por quê. Somente com um olho e muita coisa pendurada no outro eu não tinha noção do meu diâmetro. Mas isso só seria possível num tipo de participação assim porque se fosse um personagem maior talvez ficasse cansativo pro espectador. Ele entra como um tempero pra história, como é o personagem, o personagem na peça ele dá um gás $e$ depois some (NANINI, 2001). 


\section{Considerações finais: sobre atuação e mediação videotecnológica}

Como destaquei em outro momento (OROFINO, 2005) o uso que faço do conceito de mediação videotecnológica está bastante relacionado ao conceito de prática social conforme formulado por Anthony Giddens a partir de uma teoria da estruturação. Com esta articulação busco compreender os nexos entre as ações dos agentes-sujeitos em uma relação dialética com as estruturas, no sentido de que estas oferecem as regras, e também recursos que são utilizados de acordo com seus interesses (GIDDENS, 1989).

A pesquisa que realizei sobre a mediação videotécnológica indagava sobre o contex to da produção de determinada mensagem. Isto é, a partir de que infraestrutura técnica e com que capital tecnológico determinado audiovisual foi produzido. Esta estratégia tem o objetivo de situar os realizadores no tempoespaço, não apenas como artistas e produtores culturais em uma estrutura comercial particular, mas também como agentes sociais que compartilham de uma cultura televisual em comum (WILLIAMS, 1975) e que são também receptores de TV, com uma herança sócio-histórica, um mesmo repertório em comum com as audiências por eles e elas endereçadas. Portanto, busca-se localizar como a análise de condutas humanas, situadas na produção, podem potencialmente apontar, revelar, indicar como velhas estruturas de significação são transformadas em diálogo mesmo com as demandas sociais mais amplas.

Em diferentes momentos da minha experiência como pesquisadora de teledramaturgia eu pude confirmar a hipótese de que os agentes sociais usam as estruturas, isto é, negociam, criam estratégias e articulam relações que nem sempre reproduzem as regras pautadas pela organização/empresa ou instituição. Mas que também atendem aos seus interesses enquanto sujeitos sociais e históricos na construção de seus projetos de identidade política, autoral e artística. E isso também é valido para a discussão que faço com o foco voltado para o trabalho dos atores e das atrizes que se inserem no contexto industrial da produção cultural.

\section{Referências bibliográficas}

BONFITTO, Matteo. O ator compositor. São Paulo: Perspectiva, 2002.

GIDDENS, Anthony. A constituição da sociedade. São Paulo: Martins Fontes, 1989. . As conseqüências da modernidade. São Paulo: UNESP, 1991.

MACHADO, Arlindo. A televisão levada a sério. São Paulo: SENAC, 2001.

MARTÍN-BARBERO, Jesús. Dos meios às mediações: comunicação, cultura e hegemonia. Rio de Janeiro: Editora UFRJ, 1997. 
OROFINO, Maria Isabel. Mediações na produção de TV: um estudo sobre O Auto da Compadecida. Porto Alegre: Editora PUC-RS, 2005.

Em primeiro plano e na tela pequena: reflexões sobre o trabalho do ator no vídeo. II Jornada Latino-Americana de Estudos Teatrais. Florianópolis, FURB- UDESC, 2009. (meio digital).

OROZCO, Guillermo. Recepcion televisiva: tres aproximaciones y una razón para su estudio. México: Universidade Iberoamericana, 1991.

PAVIS, Patrice. A análise dos espetáculos. São Paulo: Perspectiva, 1996.

RIBEIRO, Walmeri Kellen. À procura da essência do ator: um estudo sobre a preparação do ator para a cena cinematográfica. Dissertação de Mestrado. Instituto de Artes: Universidade Estadual de Campinas, 2005.

WILLIAMS, Raymond. Television, technology and cultural form. New York: Schocken Books, 1975.

\section{Entrevistas}

CARDOSO, Rogério. Entrevista concedida a Isabel Orofino. Rio de Janeiro, fevereiro de 2001. Entrevista.

MELO, Selton. Entrevista cedida a Isabel Orofino. Rio de Janeiro, fevereiro de 2001. Entrevista.

NANINI, Marco. Entrevista cedida a Isabel Orofino. Rio de Janeiro, fevereiro de 2001. Entrevista. 